Original article

\title{
Are punitive parenting and stressful life events environmental risk factors for obsessive-compulsive symptoms in youth? A longitudinal twin study
}

\author{
G.C. Krebs ${ }^{\mathrm{a}, \mathrm{b}, 1}$, L.J. Hannigan ${ }^{\mathrm{a}, \mathrm{c}, 1}$, A.M. Gregory ${ }^{\mathrm{d}}$, F.V. Rijsdijk ${ }^{\mathrm{a}}$, B. Maughan ${ }^{\mathrm{a}}$, T.C. Eley ${ }^{\mathrm{a}, *}$ \\ a King's College London, MRC Social, Genetic and Developmental Psychiatry Centre, Institute of Psychiatry, Psychology \& Neuroscience, De Crespigny Park, \\ London, UK \\ ${ }^{\mathrm{b}}$ National and Specialist OCD and Related Disorders Clinic for Young People, South London and Maudsley NHS Foundation Trust, London, UK \\ ${ }^{\mathrm{c}}$ Institute of Health and Wellbeing, University of Glasgow, UK \\ d Department of Psychology, Goldsmiths, University of London, UK
}

\section{A R T I C LE I N F O}

\section{Article history:}

Received 31 July 2018

Received in revised form 12 November 2018

Accepted 13 November 2018

Available online 26 November 2018

\section{Keywords:}

Obsessive-compulsive disorder

Stressful life events

Parenting

Adolescence

Etiology

Genetics

\begin{abstract}
A B S T R A C T
Background: Punitive parenting and stressful life events are associated with obsessive-compulsive symptoms (OCS). However, the lack of longitudinal, genetically-informative studies means it remains unclear whether these factors represent environmentally-mediated risks for the development of OCS. Methods: Twins and siblings from the Genesis1219 study completed self-report questionnaires two years apart (Time 1: $N=2616$, mean age $=15.0$; Time $2: N=1579$, mean age $=17.0$ years) assessing OCS, maternal and paternal punitive parenting, and dependent stressful life events. Multiple regression models tested cross-sectional and longitudinal associations between the putative environmental risk factors and obsessive-compulsive symptoms using: (a) individual scores; and (b) monozygotic twin difference scores. The aetiologies of significant phenotypic associations between putative risk factors and OCS were further examined using multivariate genetic models.

Results: At a phenotypic level, maternal and paternal punitive parenting and stressful life events were all associated with OCS both cross-sectionally and longitudinally. However, only stressful life events predicted the subsequent development of OCS, after controlling for earlier symptoms. Genetic models indicated that the association between life events and change in OCS symptoms was due to both genetic (48\%) and environmental (52\%) influences. Overall, life events associated with change in OCS accounted for $1.2 \%$ of variation in OCS at Time 2 .

Conclusions: Stressful life events, but not punitive parenting, predict OCS change during adolescence at a phenotypic level. This association exists above and beyond genetic confounding, consistent with the hypothesis that stressful life events play a causal role in the development of obsessive-compulsive symptoms.
\end{abstract}

(c) 2018 The Authors. Published by Elsevier Masson SAS. This is an open access article under the CC BY license (http://creativecommons.org/licenses/by/4.0/).

\section{Introduction}

It is well-established that obsessive-compulsive disorder (OCD) is influenced by genetic factors, with twin studies suggesting they account for approximately $45-65 \%$ of the variance in OCD symptoms in youth [1]. As well as demonstrating genetic influence on OCD, these studies also highlight the importance of the

\footnotetext{
* Corresponding author at: Social, Genetic and Developmental Psychiatry Centre, Institute of Psychiatry, King's College London, Box PO80, De Crespigny Park, London SE5 8AF, UK.

E-mail address: thalia.eley@kcl.ac.uk (T.C. Eley).

1 Georgina Krebs and Laurie Hannigan are joint first authors.
}

environment, particularly child-specific or 'non-shared' environmental factors [1]. However, surprisingly little is known about the specific aspects of the non-shared environment involved in OCD. Indeed, a recent systematic review concluded that no environmental risk factors for OCD have been compellingly demonstrated, and emphasised the need for longitudinal, population-based, genetically-informative studies [2].

Two putative environmental risk factors for OCD are maladaptive parenting and stressful life events [2]. OCD is associated with maladaptive parenting, particularly overprotection and rejection [2-4]. However, most studies have utilised retrospective report of childhood parenting experiences in adults with OCD, permitting possible recall bias. Furthermore, overreliance on cross-sectional data means that the direction of effects remains unclear. While 
parenting may influence offspring $O C D$, child behaviours may also shape parenting $[5,6]$. For example, parenting practices have been shown to be affected by child anxiety [7-9]. Finally, associations may arise as a result of the same genes influencing parenting behaviours in adults and the development of OCD symptoms in children [5,10]. Transmission of these genes from parents to children would give rise to an association between the two that reflects genetic rather than environmental risk.

Stressful life events have also been linked to OCD [2]. Again, most studies have been cross-sectional and used retrospective assessment. The only two longitudinal studies to date found prospective associations between life events and later OCD [11,12]. However, life events are also known to be influenced by genetic factors [7], which could thus confound the association with OCD. Only two studies of life events and OCD have attempted to control for genetic confounding $[13,14]$. Both studies used a withinidentical twin pair design to control for familial effects, and identified associations between obsessive-compulsive symptoms (OCS) and retrospectively reported abuse and family disruption $[13,14]$. These studies provide preliminary evidence that certain stressful life events may be associated with OCS independent of familial effects, raising the possibility that they may be 'true' environmental risk factors. However, both studies were crosssectional and used retrospective reports of childhood events.

In summary, maladaptive parenting and stressful life events appear to be associated with OCS, but most previous studies have relied on cross-sectional and retrospective designs, and few are genetically-informative. Thus, it remains unclear whether these factors represent true environmental risks for the development of OCS. The current study used a longitudinal, genetically-sensitive design to examine the relationship between maternal and paternal punitive discipline, stressful life events, and OCS during adolescence. The study had two broad aims. First, we tested whether punitive discipline and stressful life events were associated with OCS in adolescence at a phenotypic level. We hypothesized that punitive parenting and stressful life events would independently predict OCS both cross-sectionally and longitudinally. Second, we examined whether these associations remained significant after controlling for familial factors, and sought to directly estimate the aetiological influences mediating these associations. We hypothesized that punitive parenting and stressful life events would remain significant predictors of OCS even after accounting for familial confounds.

\section{Methods}

\subsection{Participants}

Participants were taken from the Genesis1219 project (G1219), a longitudinal study of twins and siblings. Recruitment and selection procedures have been described previously [15]. Ethical approval was given by the Institute of Psychiatry and South London and Maudsley NHS Trust Research Ethics Committee. Informed consent was obtained from parents of adolescents under 16 years and participants over 16 . Twin zygosity was determined using parental ratings of physical similarity across two time-points [16].

The current study included data from waves 2 and 3 , hereafter referred to as Time 1 and Time 2 respectively. An OCS measure was completed by 2616 participants at Time 1 (689 MZ twins, 1267 dizygotic (DZ) twins, 576 full siblings (FS), and 84 unknown) and 1579 participants at Time 2 (439 MZ twins, $816 \mathrm{DZ}$ twins, $299 \mathrm{FS}$ and 25 unknown). The mean age was 15.0 years $(S D=1.35$; range $=13-17)$ and 17.0 years $(S D=1.17$; range $=15-19$ ), and the sample was $56 \%$ and $60 \%$ female at Times 1 and 2 respectively. Attrition was predicted by being male, being older, lower socioeconomic status, lower OCS at
Time 1, and more stressful life events at Time 1 (see Table A1 in Appendix A). Of note, the magnitude of difference in scores between those who did and did not remain in the study was small for OCS $(M=3.86$ versus 3.77$)$ and stressful life events $(M=1.13$ versus 1.36$)$.

\subsection{Measures}

\subsubsection{Obsessive-compulsive symptoms}

OCS was measured at Time 1 and 2 using the self-reported, sixitem OCS subscale of the Spence Children's Anxiety Scale [17]. Items assess a range of compulsions (e.g. checking, repeating, mental rituals) and obsessions (e.g. fear of negative events, experiencing negative mental pictures) and are scored on a 4point scale, yielding a total between 0 and 18. The subscale has good internal consistency and test-retest reliability (Spence, 1998) and correlates well with the Children's Yale-Brown ObsessiveCompulsive Scale, a clinician-administered measure of OCD severity [18]. Internal consistency in our sample was high (Cronbach's alpha $=.76$ and 0.77 at Time 1 and 2, respectively).

\subsubsection{Punitive parenting}

Parental punitive discipline was assessed at Time 1 using an adolescent-report, five-item measure of negative sanctions $[10,19,20]$, adapted from a previously well-validated parent-child relationship measure [21]. Items assess the frequency with which punitive discipline methods are utilized (e.g. yelling at or ridiculing the child) and are scored on a 5-point scale, giving a total 0 and 20. The punitive discipline measure was completed by adolescents with respect to mothers and fathers separately; Cronbach's alpha was 0.68 and .74 , respectively.

\subsubsection{Stressful life events}

Adolescents completed the Life Event Scale for Adolescents [22] at both time-points. This measure includes 12 "dependent" stressful events, which are events that can be influenced by the individual's behaviour (e.g. breaking up with a boyfriend or girlfriend, failing end of year exams) [23], and 12 stressful independent events. Since most independent life events represent experiences necessarily common to both twins/siblings (e.g. parental divorce), they are unsuitable for twin analyses and were excluded. A subscale score for dependent stressful life events was calculated by summing the number of events reported on the relevant 12 items [23].

\subsection{Statistical analyses}

\subsubsection{Phenotypic analyses}

We examined phenotypic associations between putative risk factors (maternal punitive discipline, paternal punitive discipline and stressful life events) and OCS at Times 1 and 2 using separate univariate linear regressions. Risk factors were then entered into a multiple linear regression model to determine whether they independently predicted OCS at both time-points. Longitudinal analyses involved a second multiple linear regression, testing whether putative risk factors independently predicted later OCS, while controlling for earlier OCS. The Time 2 measure of life events was used for longitudinal analyses in order to test whether events occurring between Time 1 and Time 2 predicted subsequent increases in OCS. Phenotypic analyses were conducted with the whole sample (i.e. all twins and siblings).

\subsection{2. $M Z$ twin differences analyses}

Phenotypic analyses were repeated using MZ twin difference scores, which effectively control for genetic and shared environmental factors. Since MZ twins are genetically identical and share 
their rearing environment, differences between members of an MZ twin pair must result from non-shared environmental influences. The MZ twin differences design is therefore a useful tool for isolating non-shared environmental effects. Relative MZ twin difference scores were calculated by randomly assigning twin members as Twin 1 and Twin 2, and subtracting the score of Twin 2 from that of Twin 1.

\subsubsection{Multivariate genetic modelling}

To further explore the nature of the phenotypic associations between OCS and risk factors, and increase statistical power by including the DZ twins and siblings in the sample, we applied multivariate twin models to the data. The twin design compares the degree of phenotypic similarity between MZ twins, who share $100 \%$ of their genes, with DZ twins and FS, who shared $50 \%$ of their segregating genes on average [24]. Within-pair correlations for MZ twins are compared with within-pair correlations for DZ twins and FS in order to estimate the effects of: additive genetic factors (A); shared environment $(C)$, defined as aspects of the environment resulting in phenotypic similarity between siblings; and nonshared environment (E), defined as environmental factors that give rise to phenotypic differences between siblings. Greater MZ compared to DZ/FS phenotypic similarity is attributed to genetic effects. Within-pair similarity that is not accounted for by genetic factors is attributed to shared environmental effects. Non-shared environmental effects, which are estimated from the within-pair differences between MZ twins, also include measurement error.

Putative risk factors which were significant, independent predictors of OCS in (a) cross-sectional and (b) longitudinal phenotypic analyses were included in the genetic models. A multivariate correlated factors solution was used for crosssectional data. This model tests the extent to which phenotypic correlations between variables are due to correlations among the genetic and environmental factors that influence each of them. Thus, we could directly estimate the extent to which links between putative risk factors and OCS were mediated by genetic or environmental factors. We used a multivariate Cholesky decomposition for longitudinal data. In this model, genetic and environmental components for each variable are able to influence all subsequent variables, ordered according to their chronology. Thus, we could directly estimate the aetiology of the association between risk factors and OCS at Time 2, while controlling for the stable influence of aetiological factors from OCS at Time 1.

Phenotypic and MZ twin difference analyses were conducted using STATA version 14.1. Maternal and paternal punitive discipline were normally distributed but OCS and stressful life events at showed positive skew Time 1 and 2 and were therefore logtransformed (see Table A2 in Appendix A). All variables were standardised for ease of comparison. For phenotypic analyses, a robust cluster option was used to account for the non-independence of twins/siblings. All genetic modelling was conducted within R using OpenMx [25]. All analyses controlled for age and sex as is standard practice with twin data since failure to correct for age and sex effects can result in overestimation of twin correlations [26].

\section{Results}

\subsection{Sample characteristics}

Table 1 shows mean scores for study variables with respect to individual scores and MZ twin difference scores. For twin differences scores, the mean always approximates to zero since random assignment ensures that cases in which Twin 1 scores higher than Twin 2 are countered by cases in which the reverse is true. Importantly, the amount of variation in difference scores demonstrates the existence of differential experience. For example, the mean difference score for OCS at Time 1 was 0.06 , showing that on average twins rate similar levels of OCS, but the SD was 3.31 meaning that approximately $32 \%$ of $\mathrm{MZ}$ twins differ by at least 3.31 points on OCS at Time 1.

\subsection{Phenotypic analyses}

Cross-sectional phenotypic associations are shown in the lefthand column of Table 2. Univariate linear regressions indicated that maternal punitive discipline, paternal punitive discipline and dependent stressful life events all showed positive associations with OCS at Time 1. Moreover, multiple regression revealed that all three factors were independently related to OCS.

Longitudinal phenotypic associations are shown in the righthand column of Table 2. Again, univariate regressions demonstrated that maternal punitive discipline, paternal punitive discipline and dependent stressful life events were all associated with subsequent OCS (i.e. OCS at Time 2). However, multiple regression revealed that only maternal punitive discipline and stressful life events uniquely predicted variance in later OCS. A second multiple regression showed that when controlling for OCS at Time 1, only stressful life events predicted OCS at Time 2, suggesting that exposure to more stressful life events predicts the subsequent reporting of increased OCS.

\subsection{MZ twin difference analyses}

When controlling for genetic and shared environmental influences using MZ twin difference scores, neither paternal nor

Table 1

Descriptive statistics for study variables.

\begin{tabular}{|c|c|c|c|c|c|c|}
\hline & \multicolumn{3}{|c|}{ Individual scores for whole sample } & \multicolumn{3}{|c|}{ MZ twin difference scores } \\
\hline & Mean & SD & Range & Mean & SD & Range \\
\hline \multicolumn{7}{|l|}{ Time 1} \\
\hline OCS & 3.83 & 3.18 & $0-18$ & -0.06 & 3.31 & $-13-15$ \\
\hline Maternal punitive discipline & 7.00 & 4.30 & $0-20$ & -0.07 & 3.76 & $-14-13$ \\
\hline Paternal punitive discipline & 7.16 & 3.77 & $0-20$ & 0.25 & 4.05 & $-15-13$ \\
\hline Stressful life events & 1.22 & 1.41 & $0-9$ & -0.06 & 1.46 & $-6-5$ \\
\hline \multicolumn{7}{|l|}{ Time 2} \\
\hline OCS & 3.08 & 2.96 & $0-18$ & -0.33 & 2.97 & $-10-9$ \\
\hline Stressful life events & 1.24 & 1.38 & $0-8$ & -0.12 & 1.30 & $-4-3$ \\
\hline
\end{tabular}

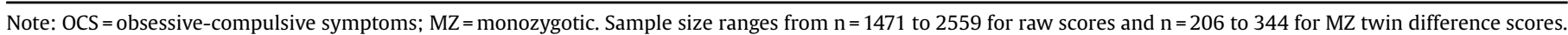
Summary statistics are presented on untransformed variables for comparison with other published samples. 
Table 2

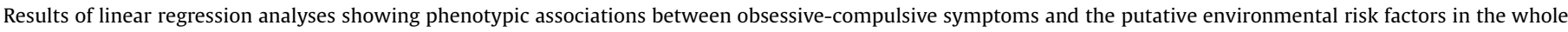
sample.

\begin{tabular}{|c|c|c|c|c|c|c|c|c|}
\hline & \multicolumn{4}{|c|}{$\begin{array}{l}\text { Cross-sectional association } \\
\text { (OCS at Time } 1)\end{array}$} & \multicolumn{4}{|c|}{$\begin{array}{l}\text { Longitudinal associations } \\
\text { (OCS at Time 2) }\end{array}$} \\
\hline & $\beta$ & $t$ & $p$ & $\mathrm{R}^{2}$ & $\beta$ & $t$ & $p$ & $\mathrm{R}^{2}$ \\
\hline \multicolumn{9}{|l|}{ Univariate linear regressions } \\
\hline Factor 1: Maternal punitive discipline at Time 1 & .19 & 8.34 & $<.001$ & .04 & .15 & 5.52 & $<.001$ & .02 \\
\hline Factor 1: Paternal punitive discipline at Time 1 & .16 & 6.76 & $<.001$ & .03 & .12 & 4.19 & $<.001$ & .01 \\
\hline Factor 1: Dependent stressful life events at Time $1 / 2^{1}$ & .24 & 11.65 & $<.001$ & .06 & .23 & 8.90 & $<.001$ & .05 \\
\hline \multicolumn{9}{|l|}{ Multiple linear regressions } \\
\hline Factor 1: Maternal punitive discipline at Time 1 & .10 & 3.65 & $<.001$ & .08 & .09 & 2.73 & $<.01$ & .07 \\
\hline Factor 2: Paternal punitive discipline at Time 1 & .07 & 2.60 & $<.01$ & & .05 & 1.39 & .17 & \\
\hline Factor 3: Dependent stressful life events at Time $1 / 2^{1}$ & .21 & 9.48 & $<.001$ & & .21 & 7.77 & $<.001$ & \\
\hline Factor 1: OCS at Time 1 & $\mathrm{~N} / \mathrm{A}$ & & & & .44 & 18.49 & $<.001$ & .25 \\
\hline Factor 2: Maternal punitive discipline at Time 1 & & & & & .02 & 0.69 & .49 & \\
\hline Factor 3: Paternal punitive discipline at Time 1 & & & & & .02 & 0.53 & .59 & \\
\hline Factor 4: Dependent stressful life events at Time 2 & & & & & .16 & 6.64 & $<.001$ & \\
\hline
\end{tabular}

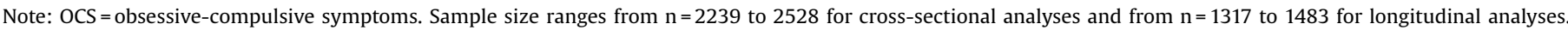
Analyses corrected for relatedness in twin pairs using robust clustering. All analyses controlled for age and gender.

1 Dependent stressful life events reported at Time 1 were used for cross-sectional analyses. Dependent stressful life events reported at Time 2 were used for longitudinal analyses, in order to test whether life events that occurred between Time 1 and Time 2 predicted increased OCS.

Table 3

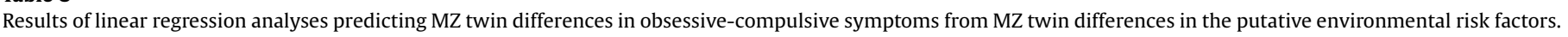

\begin{tabular}{|c|c|c|c|c|c|c|c|c|}
\hline & \multicolumn{4}{|c|}{$\begin{array}{l}\text { Cross-sectional analyses } \\
\text { (OCS at Time } 1 \text { ) }\end{array}$} & \multicolumn{4}{|c|}{$\begin{array}{l}\text { Longitudinal associations } \\
\text { (OCS at Time } 2 \text { ) }\end{array}$} \\
\hline & $\beta$ & $t$ & $p$ & $\mathrm{R}^{2}$ & $\beta$ & $t$ & $p$ & $\mathrm{R}^{2}$ \\
\hline \multicolumn{9}{|l|}{ Univariate linear regressions } \\
\hline Factor 1: Maternal punitive discipline at Time 1 & .06 & 1.17 & .24 & .00 & .11 & 1.68 & .10 & .02 \\
\hline Factor 1: Paternal punitive discipline at Time 1 & .09 & 1.63 & .10 & .01 & .06 & .82 & .41 & .01 \\
\hline Factor 1: Dependent stressful life events at Time $1 / 2^{\mathrm{a}}$ & .22 & 4.07 & $<.001$ & .05 & .18 & 2.38 & $<.05$ & .03 \\
\hline \multicolumn{9}{|l|}{ Multiple linear regressions } \\
\hline Factor 1: Maternal punitive discipline at Time 1 & -.00 & -.02 & .99 & .05 & .10 & 1.22 & .23 & .06 \\
\hline Factor 2: Paternal punitive discipline at Time 1 & .05 & .71 & .48 & & .01 & .13 & .90 & \\
\hline Factor 3: Dependent stressful life events at Time $1 / 2^{\mathrm{a}}$ & .20 & 3.40 & $<.01$ & & .17 & 1.90 & .06 & \\
\hline Factor 1 : OCS at Time 1 & $\mathrm{~N} / \mathrm{A}$ & & & & .43 & 6.42 & $<.001$ & .26 \\
\hline Factor 2: Maternal punitive discipline at Time 1 & & & & & .15 & 1.92 & .06 & \\
\hline Factor 3: Paternal punitive discipline at Time 1 & & & & & -.06 & -.79 & .43 & \\
\hline Factor 4: Dependent stressful life events at Time 2 & & & & & .07 & .87 & .38 & \\
\hline
\end{tabular}

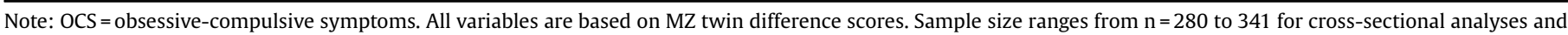
from $n=156$ to 190 for longitudinal analyses. All analyses controlled for age and gender.

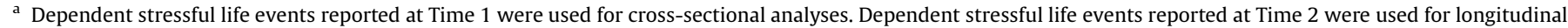
analyses, in order to test whether life events that occurred between Time 1 and Time 2 predicted increases in OCS.

maternal punitive discipline were significantly associated with OCS at Time 1 (see left-hand column of Table 3). However, the association between stressful life events and OCS remained significant.

Longitudinal analyses of MZ twin difference scores are shown in the right-hand column of Table 3. Univariate regressions indicated that only stressful life events were significantly associated with later OCS. This association did not remain significant when controlling for earlier OCS.

\subsection{Multivariate genetic modelling}

Significant predictors from the multivariate regression of OCS at Time 1 (maternal punitive discipline, paternal punitive discipline and stressful life events) were included in a multivariate correlated factors model to establish the aetiologies of their cross-sectional links with OCS. An ACE model provided the best fit for the data. Since we observed universally non-significant contributions to covariance from $\mathrm{C}(\mathrm{rC})$, we tested a more parsimonious ACE model fixing $\mathrm{rC}$ to zero. This model provided the best fit to the data (see see Table A3 in Appendix A). Estimates from the model are shown in Fig. 1. Genetic effects accounted for the majority of the phenotypic covariance between OCS and each of maternal punitive discipline, paternal punitive discipline and stressful life events (75\%, 65\% and 63\%, respectively). Importantly, the non-shared environmental effects were also significant, explaining 25\%, 35\% and $37 \%$ of the phenotypic association, respectively.

Phenotypic analyses indicated that stressful life events predicted OCS at Time 2, after controlling for OCS at Time 1. A trivariate Cholesky decomposition was used to determine the aetiology of this association. An AE model provided the best fit for the data (see Table A4 in Appendix A). Estimates from the model are shown in Fig. 2. Path tracing showed that the unique phenotypic association between stressful life events and later OCS, after controlling for OCS at Time 1, was influenced by both genetic and non-shared environmental factors (48\% and 52\%, respectively). After accounting for genetic and non-shared environmental influences on OCS at Time 1, the additional nonshared environment factors associated with stressful life events at Time 1 accounted for $1.21 \%$ of the variance in OCS at Time 2 (i.e. $0.11^{2}$ x 100). The additional genetic influences also accounted for $1.21 \%$ of the variance in later OCS. 


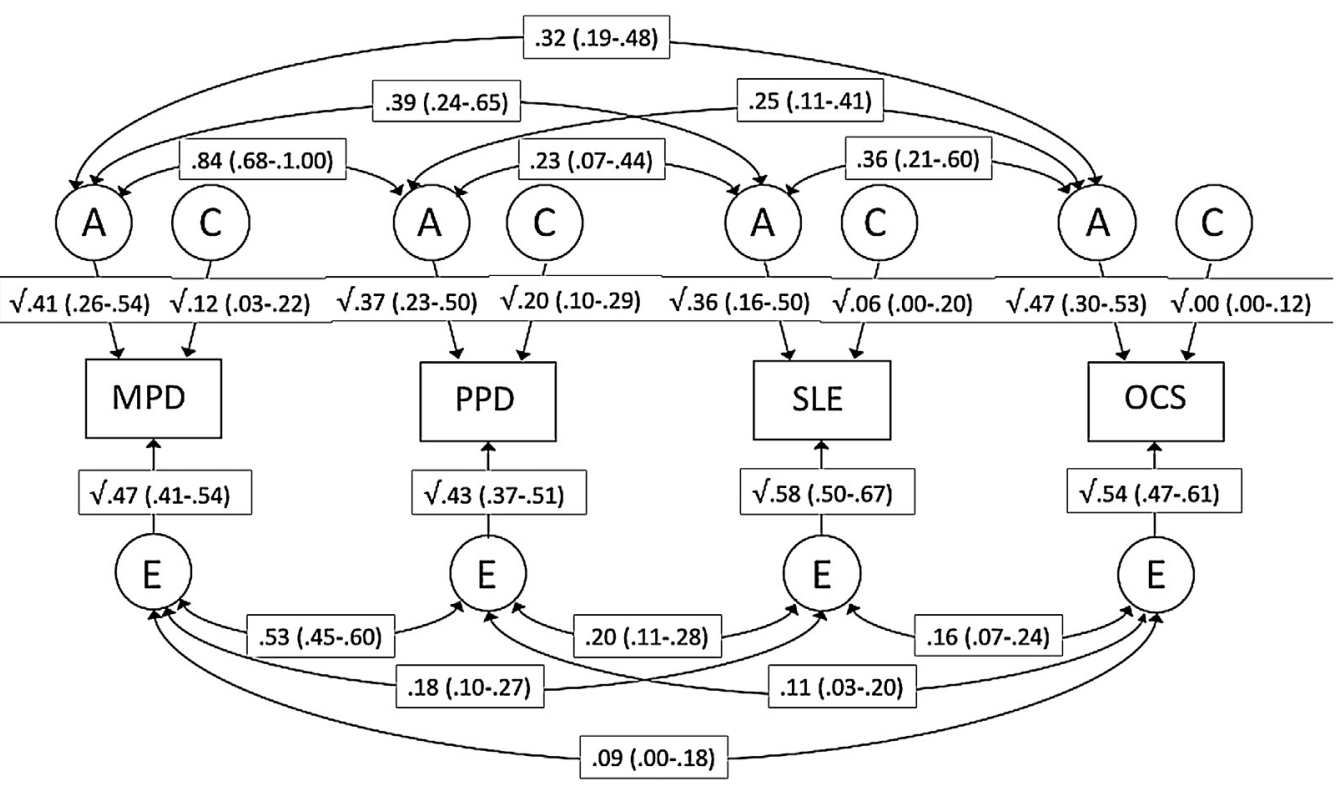

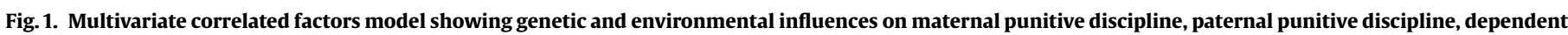
stressful life events and obsessive-compulsive symptoms (all at Time 1).

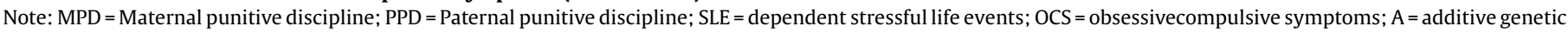

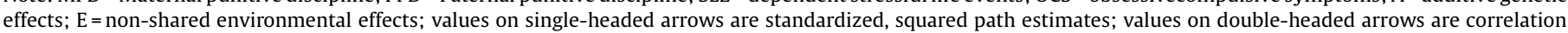
coefficients; $95 \%$ confidence intervals in parentheses. Shared environmental correlations were fixed to zero.

\section{Discussion}

This is the first study to attempt to isolate environmental effects on OCS using a longitudinal, genetically-informative design. Specifically, we aimed to clarify the extent to which punitive parenting and dependent stressful life events predict the development of OCS in adolescence, controlling for genetic and shared environmental influences.

Regarding our first aim, as hypothesised maternal punitive discipline, paternal punitive discipline and stressful life events all showed significant, independent phenotypic associations with adolescent OCS at Time 1 . This is consistent with previous findings that negative parenting $[3,4]$ and stressful life events $[13,14]$ are related to $O C D$. With respect to longitudinal associations, contrary to our hypothesis we found that only stressful life events predicted later OCS when controlling for earlier OCS. In other words, greater levels of self-reported stressful life events, but not punitive parenting, predicted increases in OCS during adolescence.

Our second aim was to test whether associations between the putative environmental risk factors and OCS remained significant after controlling for genetic and shared environmental influences. As hypothesised, our MZ twin difference analyses showed that stressful life events were positively associated with OCS at Time 1. This finding is consistent with previous studies in adults $[13,14]$, and demonstrates that the association between OCS and life events is independent of familial confounds. MZ twin difference analyses also provided partial evidence for a longitudinal association between stressful life events and OCS, controlling for familial effects. This association was significant in the univariate regression but not the multiple regressions, which could reflect reduced statistical power.

Contrary to our hypothesis, univariate regressions of MZ twin difference scores indicated that neither maternal nor paternal punitive discipline were significantly associated with OCS either cross-sectionally or longitudinally when accounting for familial confounding. This could imply that the phenotypic relationship between punitive parenting and OCS is largely driven by genetic and/or shared environmental effects. Alternatively, these analyses may have been underpowered to detect modest effects given the reduced sample size (only MZ twins). We therefore further explored genetic and environmental influences on phenotypic associations of interest using genetic models.

Results from the genetic modelling indicated that crosssectional phenotypic associations between the three putative environmental risk factors and OCS are mediated by both common genetic and non-shared environmental influences. Thus, as hypothesised, we found evidence consistent with a true environmental association of OCS with punitive parenting and dependent stressful life events. Similarly, in line with our hypothesis, the longitudinal genetic model indicated that the unique phenotypic association between stressful life events and later OCS (i.e. controlling for earlier OCS) is accounted for by both genetic and environmental factors, in roughly equal proportions. In this stringent test, stressful life events accounted for just over $1 \%$ of the variance in later OCS, independent of genetic confounds and after controlling for earlier OCS. While the magnitude of the effect is small, this is not surprising given that this analysis accounted for the stable and therefore more reliable variance. Furthermore, the genetic models include measurement error in the $\mathrm{E}$ term, potentially attenuating our estimates of non-shared environmental effects. Nevertheless, our finding is in keeping with estimates found in previous genetically informed studies of concurrent associations between life events and OCS [13]. To our knowledge, this is the first study to demonstrate that stressful life events prospectively predict the development of new OCS, when controlling for genetic effects. This finding supports the hypothesis that such experiences play a causal role in the development of OCS. Future studies should further test causality using established epidemiological criteria [27]. Additionally, further research is needed to examine the mechanisms underlying the association between stressful life events and OCS. Cognitive behavioural models propose that the impact of life events on OCS is moderated by cognitive biases [28]. This could be tested in longitudinal, genetically-informative studies using self-report measures and/ or behavioural assessments of information-processing biases. 


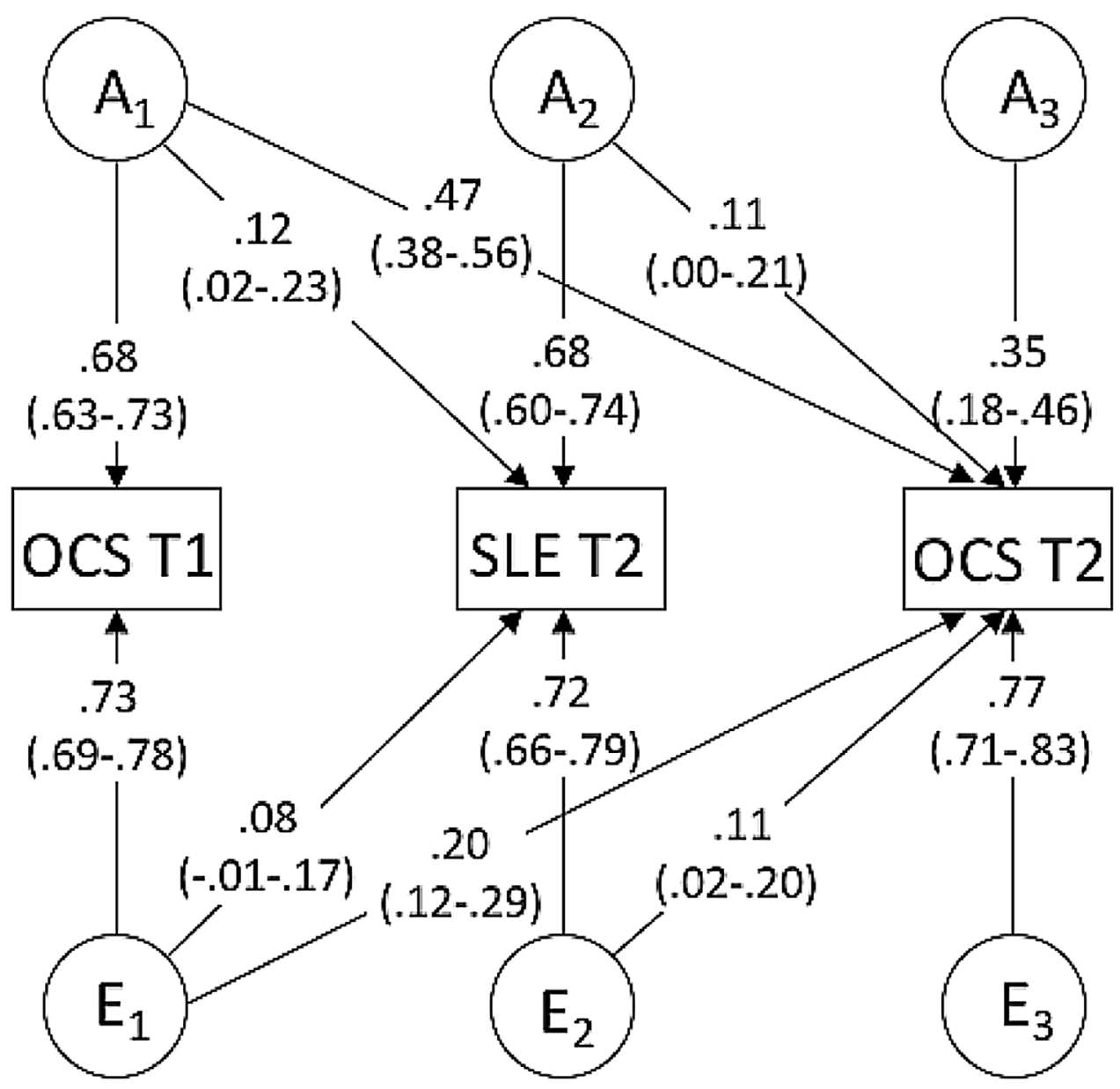

Fig. 2. Trivariate Cholesky decomposition showing genetic and environmental influences on obsessive-compulsive symptoms and stressful life events.

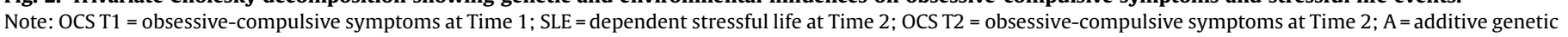
effects; $E$ = non-shared environmental effects; values are standardized, unsquared path estimates; $95 \%$ confidence intervals in parentheses

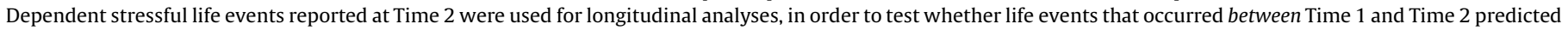
increased OCS.

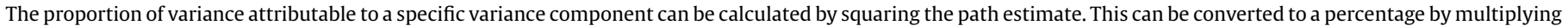
by 100 . For example, the influence of $E_{2}$ on OCS at Time 2 is $.11^{2} \times 100=1.21 \%$.

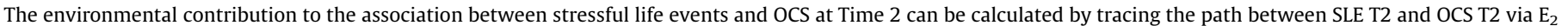
$(.72 \times .11)$ and dividing it by the combination of the paths between SLE T2 and OCS T2 via $\mathrm{A}_{2}$ and $\mathrm{E}_{2}(.68 \times .11+.71 \times .11)$.

The current findings have important implications. First, higher levels of self-reported dependent stressful life events predicted subsequent increases OCS during adolescence at a phenotypic level. Thus, stressful life events could be a clinical marker for identifying individuals at risk of developing $\mathrm{OCD}$, in conjunction with other known risk factors (e.g. family history of OCD), enhancing early intervention and long-term outcomes [29]. Second, the longitudinal association between stressful life events and OCS exists above and beyond common genetic influences, consistent with the notion that such experiences represent an environmental risk for the development of OCD. Although further research is needed to understand the mechanisms underpinning this relationship, stressful life events could be an important target for prevention programs. Lastly, we did not find evidence for punitive parenting being a risk factor for OCS, which implies that modifying such parenting behaviours is unlikely to be an effective OCD prevention strategy during adolescence.

The current study has several strengths including the prospective, genetically-informative design and inclusion of fathers, who are often overlooked in studies of parenting [30]. Nevertheless, results should be considered in the context of some limitations. First, only punitive parenting was assessed and findings may not generalise to other parenting practices (e.g. overprotective parenting). Second, our measure of stressful life events relied on retrospective reports of the previous 12 months. However, recall bias is likely to be lower compared to previous studies which retrospectively assessed life events across the life span (e.g. [13,14]. Third, our study focussed on OCS and it cannot be assumed that the results would generalise to diagnosable $O C D$, although empirical data indicate that OCD is a dimensional construct [31]. Fourth, this study only included adolescent-report measures. Reliance on a single informant may have inflated associations and future studies should utilise multiple-informant measures. Fifth, we found that participant drop out was predicted by a range of variables including OCS at Time 1 . The magnitude of effects were small but reached statistical significant due to the large sample size. Although selective attrition may have reduced the overall variance at Time 2, it is unlikely to have substantially influenced our estimates of associations [32].

In summary, the present study suggests that dependent stressful life events, but not punitive parenting, predict the subsequent reporting of increased OCS during adolescence. Furthermore, this association exists independent of genetic effects. While these findings are consistent with the notion that stressful life events play a causal role in the development of OCD, further research is needed to establish the mechanisms underlying this association. 


\section{Funding}

Waves 1-3 were funded by the W T Grant Foundation, the University of London Central Research fund and a Medical Research Council (MRC) Training Fellowship (G81/343) and Career Development Award (G120/635) to Thalia C. Eley. Georgina Krebs is funded by an MRC Clinical Research Training Fellowship (MR/N001400/1). Laurie Hannigan is supported by a $1+3 \mathrm{Ph}$.D. studentship from the UK Economic and Social Research Council(ESRC). This study presents independent research part-funded by the National Institute for Health Research (NIHR) Biomedical Research Centre at South London and Maudsley NHS Foundation Trust and King's College London. The views expressed are those of the authors and not necessarily those of the NHS, the NIHR or the Department of Health.

\section{Declarations of interest}

None.

\section{Acknowledgements}

We thank the families for their participation as well as numerous staff and students from the Social Genetic Developmental Psychiatry Centre, Institute of Psychiatry, Psychology and Neuroscience, King's College London and Goldsmiths, University of London.

\section{Appendix A}

Table A1

Results of logistic regression showing variables predicting participant drop-out between Time 1 and Time 2 .

\begin{tabular}{|c|c|c|c|}
\hline Variable & $\begin{array}{l}\text { Odds Ratio } \\
\text { (95\% confidence intervals) }\end{array}$ & $z$ & $p$ \\
\hline Sex & $1.48(1.21-1.81)$ & 3.93 & $<.001$ \\
\hline Age & $0.90(0.84-0.96)$ & -3.22 & $<.01$ \\
\hline Socioeconomic status (parental education level) & $1.06(1.01-1.12)$ & 2.25 & $<.05$ \\
\hline OCS at Time 1 & $0.97(0.94-1.00)$ & 2.43 & $<.05$ \\
\hline Maternal punitive discipline at Time 1 & $0.97(0.94-1.00)$ & -1.83 & .067 \\
\hline Paternal punitive discipline at Time 1 & $0.99(0.96-1.01)$ & -1.00 & .316 \\
\hline SLE at Time 1 & $0.48(0.32-0.72)$ & -3.52 & $<.001$ \\
\hline
\end{tabular}

Note: OCS = obsessive-compulsive symptoms; SLE = stressful life events.

Table A2

Skewness of variables before and after log transformation.

\begin{tabular}{|c|c|c|}
\hline Variable & Skewness of untransformed variable & Skewness of log transformed variable \\
\hline OCS at Time 1 & 1.19 & .34 \\
\hline OCS at Time 2 & 1.55 & .12 \\
\hline SLE at Time 1 & 1.39 & .35 \\
\hline SLE at Time 2 & 1.22 & .29 \\
\hline Maternal punitive discipline at Time 1 & .53 & $\mathrm{~N} / \mathrm{A}$ \\
\hline Paternal punitive discipline at Time 1 & .55 & $\mathrm{~N} / \mathrm{A}$ \\
\hline
\end{tabular}

Note: OCS = obsessive-compulsive symptoms; SLE = stressful life events.

Table A3

Fit comparisons for mulitvariate correlated factors models

\begin{tabular}{|c|c|c|c|c|c|c|c|}
\hline Base model & Comparison model & $-2 \mathrm{LL}$ & df & diff LL & diff df & $p$ & AIC \\
\hline Saturated model & $\mathrm{N} / \mathrm{A}$ & 25313.92 & 9553 & $\mathrm{~N} / \mathrm{A}$ & $\mathrm{N} / \mathrm{A}$ & $\mathrm{N} / \mathrm{A}$ & 6207.92 \\
\hline Saturated model & ACE model & 25375.67 & 9607 & 61.75 & 54 & 0.22 & 4181.95 \\
\hline ACE model & ACE model (No rC) & $25,379.83$ & 9613 & 4.16 & 6 & 0.66 & 6153.83 \\
\hline ACE model & AE model & 25409.94 & 9617 & 34.27 & 10 & $<.001$ & 6175.94 \\
\hline
\end{tabular}

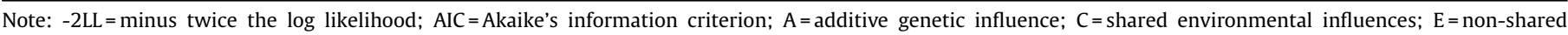
environmental influences. Bold typeface indicates the selected model.

Table A4

Fit comparisons for trivariate Cholesky decomposition models.

\begin{tabular}{|c|c|c|c|c|c|c|c|}
\hline Base model & Comparison model & $-2 \mathrm{LL}$ & df & $\operatorname{diff} L L$ & diff $d f$ & $p$ & AIC \\
\hline Saturated model & $\mathrm{N} / \mathrm{A}$ & 14869.59 & 5439 & $\mathrm{~N} / \mathrm{A}$ & $\mathrm{N} / \mathrm{A}$ & $\mathrm{N} / \mathrm{A}$ & 3991.59 \\
\hline Saturated model & ACE model & 14906.49 & 5472 & 36.9 & 33 & 0.56 & 3962.49 \\
\hline ACE model & AE model & 14906.67 & 5478 & 0.18 & 6 & 0.99 & 6480.98 \\
\hline
\end{tabular}

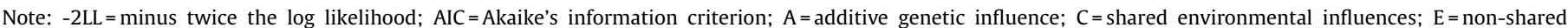
environmental influences. Bold typeface indicates the selected model. 


\section{References}

[1] van Grootheest DS, Cath DC, Beekman AT, Boomsma DI. Twin studies on obsessive-compulsive disorder: a review. Twin Res Hum Genet 2005;8:450-8.

[2] Brander G, Pérez-Vigil A, Larsson H, Mataix-Cols D. Systematic review of environmental risk factors for Obsessive-Compulsive Disorder: a proposed roadmap from association to causation. Neurosci Biobehav Rev 2016;65:3662.

[3] Alonso PM, Menchón J, Mataix-Cols D, Pifarré J, Urretavizcaya M, Crespo JM, et al. Perceived parental rearing style in obsessive-compulsive disorder: relation to symptom dimensions. Psychiatry Res 2004;127:267-78.

[4] Lennertz L, Grabe HJ, Ruhrmann S, Rampacher F, Vogeley A, SchulzeRauschenbach S, et al. Perceived parental rearing in subjects with obsessivecompulsive disorder and their siblings. Acta Psychiatr Scand 2010;121:280-8.

[5] Eley TC, Napolitano M, Lau JY, Gregory AM. Does childhood anxiety evoke maternal control? A genetically informed study. J Child Psychol Psychiatry 2010;51:772-9.

[6] Natsuaki MN, Leve LD, Harold GT, Neiderhiser JM, Shaw DS, Ganiban J, et al. Transactions between child social wariness and observed structured parenting: evidence from a prospective adoption study. Child Dev 2013;84:1750-65.

[7] Kendler KS, Baker JH. Genetic influences on measures of the environment: a systematic review. Psychol Med 2007;37:615-26.

[8] Hannigan LJ, McAdams TA, Plomin R, Eley TC. Etiological influences on perceptions of parenting: a longitudinal, multi-informant twin study. J Youth Adolesc 2016;45:2387-405.

[9] Avinun R, Knafo A. Parenting as a reaction evoked by children's genotype. Personal Soc Psychol Rev 2014;18:87-102.

[10] Lau JY, Eley TC. Disentangling gene-environment correlations and interactions on adolescent depressive symptoms. J Child Psychol Psychiatry 2008;49:14250.

[11] Grisham JR, Fullana MA, Mataix-Cols D, Moffitt TE, Caspi A, Poulton R. Risk factors prospectively associated with adult obsessive-compulsive symptom dimensions and obsessive-compulsive disorder. Psychol Med 2011;41:2495506.

[12] Valleni-Basile LA, Garrison CZ, Waller JL, Addy CL, McKeown RE, Jackson KL, et al. Incidence of obsessive-compulsive disorder in a community sample of young adolescents. J Am Acad Child Adolesc Psychiatry 1996;35:898-906.

[13] Vidal-Ribas P, Stringaris A, Rück C, Serlachius E, Lichtenstein P, Mataix-Cols D. Are stressful life events causally related to the severity of obsessivecompulsive symptoms? A monozygotic twin difference study. Eur Psychiatry 2015;30:309-16

[14] Cath DC, van Grootheest DS, Willemsen G, van Oppen P, Boomsma DI. Environmental factors in obsessive-compulsive behavior: evidence from discordant and concordant monozygotic twins. Behav Genet 2008;38:108-20.

[15] McAdams TA, Gregory AM, Rowe R, Zavos HM, Barclay NL, Lau JY, et al. The Genesis 12-19 (G1219) Study: a twin and sibling study of gene-environment interplay and adolescent development in the UK. Twin Res Hum Genet 2013;16:134-43.

[16] Price TS, Freeman B, Craig I, Petrill SA, Ebersole L, Plomin R. Infant zygosity can be assigned by parental report questionnaire data. Twin Res Hum Genet 2000;3:129-33.

[17] Spence SH, Barrett PM, Turner CM. Psychometric properties of the Spence Children's Anxiety Scale with young adolescents. J Anxiety Disord 2003; 17:605-25.

[18] Whiteside SPH, Gryczkowski MR, Biggs BK, Fagen R, Owusu D. Validation of the Spence Children's Anxiety Scale's obsessive compulsive subscale in a clinical and community sample. J Anxiety Disord 2012;26:111-6.

[19] Liang H, Eley TC. A monozygotic twin differences study of nonshared environmental influence on adolescent depressive symptoms. Child Dev 2005;76:1247-60.

[20] Button TMM, Lau JYF, Maughan B, Eley TC. Parental punitive discipline, negative life events and gene-environment interplay in the development of externalizing behavior. Psychol Med 2007;38:29-39.

[21] Hetherington EM, Clingempeel WG. Coping with marital transitions: a family systems perspective. Monogr Soc Res Child Dev 1992;57:1-14.

[22] Coddington RD. Measuring the stressfulness of a child's environment. In: Humphrey JH, editor. Stress in childhood. New York: AMS Press; 1984. p. 97-126.

[23] Rowe R, Maughan B, Eley TC. Links between antisocial behavior and depressed mood: the role of life events and attributional style. J Abnorm Child Psychol 2006;34:283-92.

[24] Rijsdijk FV, Sham PC. Analytic approaches to twin data using structural equation models. Brief Bioinformatics 2002;3:119-33.

[25] Boker S, Neale M, Maes H, Wilde M, Spiegel M, Brick T, et al. OpenMx: an open source extended structural equation modeling framework. Psychometrika 2011;76:306-17.

[26] McGue M, Bouchard Jr. TJ. Adjustment of twin data for the effects of age and sex. Behav Genet 1984;14:325-43.

[27] Fedak KM, Bernal A, Capshaw ZA, Gross S. Applying the Bradford Hill criteria in the 21st century: how data integration has changed causal inference in molecular epidemiology. Emerg Themes Epidemiol 2015;12:14.

[28] Beck AT, Haigh EA. Advances in cognitive theory and therapy: the generic cognitive model. Annu Rev Clin Psychol 2014;10:1-24.

[29] Micali N, Heyman I, Perez M, Hilton K, Nakatani E, Turner C, et al. Long-term outcomes of obsessive-compulsive disorder: follow-up of 142 children and adolescents. Br J Psychiatry 2010;197:128-34.

[30] Bögels S, Phares V. Fathers' role in the etiology, prevention and treatment of child anxiety: a review and new model. Clin Psychol Rev 2008;28:539-58.

[31] Abramowitz JS, Fabricant LE, Taylor S, Deacon BJ, McKay D, Storch EA. The relevance of analogue studies for understanding obsessions and compulsions. Clin Psychol Rev 2014;34:206-17.

[32] Wolke D, Waylen A, Samara M, Steer C, Goodman R, Ford T, et al. Selective drop-out in longitudinal studies and non-biased prediction of behaviour disorders. Br J Psychiatry 2009;195:249-56. 